\title{
Hydrogen bonded supramolecular elastomers : correlating hydrogen bonding strength with morphology and rheology
}

Article

Accepted Version

Woodward, P., Hermida-Merino, D., Greenland, B. W., Hamley, I. W., Light, Z., Slark, A. and Hayes, W. (2010) Hydrogen bonded supramolecular elastomers : correlating hydrogen bonding strength with morphology and rheology. Macromolecules, 43 (5). pp. 2512-2517. ISSN 0024-9297 doi: https://doi.org/10.1021/ma9027646 Available at https://centaur.reading.ac.uk/16417/

It is advisable to refer to the publisher's version if you intend to cite from the work. See Guidance on citing.

To link to this article DOI: http://dx.doi.org/10.1021/ma9027646

Publisher: American Chemical Society

All outputs in CentAUR are protected by Intellectual Property Rights law, including copyright law. Copyright and IPR is retained by the creators or other copyright holders. Terms and conditions for use of this material are defined in the End User Agreement. 


\section{CentAUR}

Central Archive at the University of Reading

Reading's research outputs online 


\title{
Hydrogen bonded supramolecular elastomers - Correlating hydrogen bonding strength with morphology and rheology
}

Philip J. Woodward, ${ }^{\text {a }}$ Daniel Hermida Merino, ${ }^{\mathrm{a}}$ Barnaby W. Greenland, ${ }^{\mathrm{a}}$ Ian W. Hamley, ${ }^{\mathrm{a}}$ Zoe Light, ${ }^{\mathrm{a}}$ Andrew T. Slark ${ }^{\mathrm{b}}$ and Wayne Hayes ${ }^{\mathrm{a} *}$

${ }^{a}$ Department of Chemistry, University of Reading, Whiteknights, Reading, RG6 6AD (UK). Fax: (+44) 118-378-6331; E-mail: w.c.hayes@reading.ac.uk ${ }^{\mathrm{b}}$ Henkel UK Limited, Wexham Road, Slough, SL2 5DS (UK)

\begin{abstract}
A series of six low molecular weight elastomers with hydrogen bonding end-groups have been designed, synthesised and studied. The poly(urethane) based elastomers all contained essentially the same hard block content ( $c a .11 \%)$ and differ only in the nature of their end-groups. Solution state ${ }^{1} \mathrm{H}$ NMR spectroscopic analysis of model compounds featuring the end-groups demonstrate that they all exhibit very low binding constants, in the range 1.4 to $45.0 \mathrm{M}^{-1}$ in $\mathrm{CDCl}_{3}$, yet the corresponding elastomers each possess a markedly different nanoscale morphology and rheology in the bulk. We are able to correlate small variations of the binding constant of the end-groups with dramatic changes in the bulk properties of the elastomers. These results provide an important insight into the way in which weak non-covalent interactions can be utilized to afford a range of self-assembled polyurethane based materials that feature different morphologies.
\end{abstract}

\section{Introduction}

Supramolecular polymer chemistry has become a major field of research in recent years. ${ }^{1}$ Typically, supramolecular polymers consist of relatively low molecular weight species which are able to spontaneously assemble into higher ordered structures through designed motifs that can form reversible non-covalent bonds. ${ }^{2}$ Supramolecular materials utilizing hydrogen bonding interactions have received ${ }^{3,4}$ the most widespread attention, but in principle, any non-covalent bond forming process could be employed, as demonstrated by the synthesis of materials harnessing the dynamic nature of metal-ligand complexation $^{5}$ and $\pi-\pi$ stacking $^{6}$ interactions to form supramolecular materials. 
As with conventional, covalently bonded polymers, the macroscopic properties of supramolecular polymers (such as viscosity and tensile strength) are intimately related to the degree of polymerisation (DP). For supramolecular polymers in dilute solution, the relationship between monomer concentration ([M]) and DP and the can be approximated ${ }^{7}$ to be proportional to $\left(K_{\mathrm{a}}[\mathrm{M}]\right)^{0.5}$, where $K_{\mathrm{a}}$ is the association constant of the monomers. In these systems, $K_{\mathrm{a}}$ can be altered by the application of an external stimulus which directly affects the physical properties of the polymer. Subsequent removal of the stimulus allows the supramolecular bonds between the monomers to reform, thus restoring the original mechanical properties of the material. This characteristic affords supramolecular systems with reversibly switchable physical properties, a feature which cannot be achieved easily though conventional covalent polymer synthesis. As a consequence of the relationship between DP and $K_{\mathrm{a}}$, early studies in this field focused on increasing the binding constant between the monomeric components of the supramolecular polymer. This resulted in the production of materials with solution state properties analogous to those of conventional high molecular weight covalently bonded polymers. As a result, carefully designed, highly pre-organised hydrogen bonding motifs that exhibit high binding constants $\left(<10^{6} \mathrm{M}^{-1}\right)$ were reported by the groups of Meijer and Sijbesma ${ }^{8}$ and Zimmerman. ${ }^{9}$ Bulk supramolecular polymers that are assembled from monomers which exhibit high binding constants require significant energy to disrupt the supramolecular assembly. Thus, disassembly of the supramolecular complexes to give dramatic changes in viscosity requires high temperatures (for example, ${ }^{10}$ the storage modulus (G') of a supramolecular complex comprised of tetraethylene glycol bis(4-benzoic acid) and 2,2',6,6'-tetrakis[ (4-pyridylmethylene) iminolphenoxylbiphenyl] only decreased by an order of magnitude when the temperature is increased from $150{ }^{\circ} \mathrm{C}$ to $190{ }^{\circ} \mathrm{C}\left(4.5 \times 10^{6}\right.$ to $\left.2 \times 10^{5} \mathrm{~Pa}\right)$.

Whilst the relationship between DP, $K_{\mathrm{a}}$ and the physical characteristics of supramolecular polymers in dilute solution is well understood, the same rational cannot be applied directly to the prediction of bulk properties of the materials. In the solid state, polymer morphology and crystallinity play equally important rôles in the final properties of the material. Early reports of these relationships include studies by Lillya et al. who found ${ }^{11}$ 
that the addition of simple benzoic acid residues to low molecular weight poly(tetrahydrofuran) (PTHF) $\left(\mathrm{M}_{\mathrm{n}} \approx 2000 \mathrm{Da}\right)$ transformed the waxy parent polymer to an elastomeric solid. The strength of the material is derived from crystallization of the end-groups into hard microdomains ${ }^{12}$ which afford the polymer a three dimensional network structure. Rheological analysis demonstrated that the storage modulus for the self-assembled material decreased from $10^{6} \mathrm{~Pa}$ to $\approx 0 \mathrm{~Pa}$ between 50 and $70{ }^{\circ} \mathrm{C}$. Dramatic changes in viscosity such as this, over readily accessible temperatures represent a genuine advantage for large scale polymer synthesis and processing. Since this report, stable supramolecular assemblies generated by phase segregation driven by crystallinity and hydrogen bonding have been studied by several groups. ${ }^{13,14,15}$ Notably, Rowan et al. have demonstrated the ability to harness the co-operative power of multiple weak hydrogen bonding units $\left(\approx 5 \mathrm{M}^{-1}\right)$ from the addition of adenine derivatives to PTHF $\left(\mathrm{M}_{\mathrm{n}}=1,400 \mathrm{~g}\right.$ $\left.\mathrm{mol}^{-1}\right){ }^{16}$ This procedure transformed soft waxy PTHF into a highly thermally sensitive material which was mechanically stable at ambient operating temperatures $\left(\mathrm{G}^{\prime}\right.$ is $c a .10^{6}$ at $\left.120^{\circ} \mathrm{C}\right)$.

We have recently reported the synthesis of a series of low molecular weight (<650 Da) bisurethane derivatives via a simple one-pot procedure from inexpensive and readily available starting materials. ${ }^{17}$ Extensive ${ }^{1} \mathrm{H}$ NMR, IR spectroscopic and viscometric analysis demonstrated that these bisurethane species assembled into extended hydrogen bonded networks both in solution and in bulk. Rheological analysis in the bulk revealed that these bisurethanes behaved in an analogous fashion to high molecular weight polyurethanes $\left(\mathrm{M}_{\mathrm{w}} \approx 50,000 \mathrm{~g} \mathrm{~mol}^{-1}\right)$ despite their monomeric nature and low association constants $\left(>15 \mathrm{M}^{-1}\right)$. Furthermore, we have also demonstrated ${ }^{18}$ that this bisurethane hydrogen bonding motif could be introduced readily into isocyanate terminated prepolymers. Addition of the end-group to the prepolymer was found to have a dramatic effect on the physical properties of the bulk material, transforming the viscous prepolymers into elastomers which exhibited highly temperature dependent rheological characteristics. These elastomers were synthesized through a simple procedure that involved the addition of either an alcohol or amine derivative to a prepolymer followed by isolation via precipitation. This methodology permits the rapid production of a series 
of structurally related materials enabling the influence of atomic level changes to either the hydrogen bonding 'hard' segments or the polymer 'soft' segments to be investigated in a systematic fashion. Herein we report the results of a structure-property investigation of series of self-assembling polyurethanes by correlating changes in hydrogen bonding ability on the nanostructure and mechanical properties of the bulk elastomers.

\section{General experimental}

\section{Materials}

Poly(ethylene-co-butylene) diol $\left(\mathrm{M}_{\mathrm{n}}=3500, \mathrm{M}_{\mathrm{w}} / \mathrm{M}_{\mathrm{n}}=1.08\right)$ was supplied by Henkel UK Limited. Reagents were purchased from Acros Chimica, Aldrich Chemical Company and Alfa Aesar and were used without further purification. Tetrahydrofuran (THF) was distilled from benzophenone and sodium.

\section{Characterisation}

${ }^{1} \mathrm{H}$ Nuclear magnetic resonance spectroscopy was performed on a Bruker AMX400 (400 MHz) spectrometer or a Bruker AC250 (250 MHz) spectrometer (using the deuterated solvent as lock). ${ }^{13} \mathrm{C}$ Nuclear magnetic resonance $\left({ }^{13} \mathrm{C} \mathrm{NMR}\right)$ spectroscopy was performed on Bruker AMX400 (100 MHz) spectrometer or a Bruker AC 250 operating at $62.5 \mathrm{MHz}$. Infrared spectroscopy was performed using either a Perkin Elmer 1720-X spectrometer or a Bruker Equinox 55 FT-IR microspectrometer fitted with MCT D316 IR scope detector in transmission mode. The samples were analysed as either neat films or in solution between two potassium bromide or sodium chloride disks. Gel permeation chromatography (GPC) was performed by Smithers RAPRA UK using a Viscotec TDA model 301 equipped with a PLgel guard column and two mixed bed-D (30 CM, $5 \mu \mathrm{M})$ columns. Detection was achieved using a refractive index detector with differential pressure and light scattering. The samples were analyzed at $30^{\circ} \mathrm{C}$ using $\mathrm{THF}$ as the eluent at a flow rate of $1 \mathrm{~mL} / \mathrm{min}$. The instrument was calibrated using low polydispersity polystyrene standards. Glass transition temperatures $\left(T_{\mathrm{g}}\right)$ were determined using a TA Instruments DSC 2920 differential scanning calorimeter. DSC was performed scanning from $-80{ }^{\circ} \mathrm{C}$ to $150{ }^{\circ} \mathrm{C}$ (at a rate of $3 \mathrm{~K} / \mathrm{min}$ modulated). Rheological analysis was performed on a TA Instruments AR2000 Rheometer at a constant frequency of 10 $\mathrm{Hz}$. 
SAXS experiments were performed on station 2.1 at the Synchrotron Radiation Source, Daresbury Laboratory, UK and station A-2 of HASYLAB at Deutsches ElektronenSynchrotron (DESY) in Hamburg, Germany. A two-dimensional RAPID area detector was used on station 2.1 at Daresbury to acquire SAXS patterns. WAXS data were obtained at station A-2 DESY using a linear detector. Since orientation was not observed in the SAXS patterns, data were reduced to one-dimensional form using software BSL, with appropriate background subtraction. The wavenumber $q=4 \pi \sin \theta / \lambda$ (scattering angle $2 \theta$, wavelength $\lambda=1.5 \AA$ or $1.4 \AA$ ) scale was calibrated using wet collagen (rat tail tendon).

Full synthetic procedures and characterization for the model componds can be found in the supporting information (see Supporting Information). Binding constants were determined by a dilution-titration followed by ${ }^{1} \mathrm{H}$ NMR spectroscopic analysis (see Supporting Information). These data were analysed by 'Dynofit 4' to generate the binding constant and confidence interval using the Michaelis-Menton equation:

$$
\delta[T]=\delta \max -\frac{\Delta \delta \max \times K_{a} \times[T]}{1+K_{a} \times[T]}
$$

Synthesis of isocyanate terminated pre-polymer 14. Poly(ethylene-co-butylene) diol 13 (250.0 g, $0.071 \mathrm{~mol})$ was heated at $120^{\circ} \mathrm{C}$ under vacuum for $1 \mathrm{~h}$ before MDI $(35.7 \mathrm{~g}$, $0.143 \mathrm{~mol}$ ) was added to the stirred polymer under a nitrogen atmosphere. After 60 minutes heating, a vacuum was applied for 30 minutes before the heat was removed and the system flushed with nitrogen to generate pre-polymer 14 which was then stored at -18 ${ }^{\circ} \mathrm{C}$ and used as required.

Polymers 16, 18 and 19 were prepared according to the general procedure described for 15 (see Supporting Information).

4-((4'-Carbamic acid 2-[bisbutyl-amino]-ethyl ester) benzyl)-phenyl-amino-carbonyl terminated poly(ethylene-co-butylene) diol 15. To a stirred solution of prepolymer 14 
(4.34 g, $0.362 \mathrm{mmol})$ in dry THF $(50 \mathrm{~mL})$ under a nitrogen atmosphere was added 2hydroxyethyl- $N, N$-bisbutylamine $(0.45 \mathrm{~mL}, 2.2 \mathrm{mmol})$ and the mixture was heated under reflux for $18 \mathrm{~h}$. The material produced was purified by repeated precipitation from methanol at $-78{ }^{\circ} \mathrm{C}$ to furnish the desired polymer $\mathbf{1 5}$ as a clear light brown tacky wax material (3.85 g, $71 \%)$; IR $\left(\mathrm{CDCl}_{3}, \mathrm{KBr}\right) v_{\max } / \mathrm{cm}^{-1} 2904,2855,1728,1613,1595,1523$, 1461, 1413, 1379, 1310, 1216, 1064; ${ }^{1} \mathrm{H}$ NMR (400 MHz, $\left.\mathrm{CDCl}_{3}\right) \delta$ 0.81-0.84 (m), 0.88$0.92(\mathrm{~m}), 1.03-1.26(\mathrm{~m}), 1.60-1.70(\mathrm{~m}), 2.46-2.50(\mathrm{t}, J=7.5 \mathrm{~Hz}), 2.71-2.74(\mathrm{t}, J=6.0$ $\mathrm{Hz}), 3.88$ (s), 4.12-4.22 (m), 7.09-7.20 (m), 7.26-7.29 (m); ${ }^{13} \mathrm{C}$ NMR (100 MHz, $\left.\mathrm{CDCl}_{3}\right)$ $\delta$ 10.6-11.1, 14.3, 20.9, 26.1-27.0, 29.6, 30.0-31.2, 33.5-33.8, 38.1-39.1, 40.8, 52.9, 54.7, 63.5, 63.9, 119.1, 129.6, 136.3, 136.5, 154.0; GPC (THF): $\mathrm{M}_{\mathrm{w}} 27,000, \mathrm{M}_{\mathrm{n}}$ 15,200.

Polymers 20 was prepared according to the general procedure described for 17 (see Supporting Information).

\section{4-((4'-Carbamic acid 2-[bis-(2-hydroxyethyl)-amino]-ethyl ester) benzyl)-phenyl-} amino-carbonyl terminated poly(ethylene-co-butylene) diol 17. To a stirred solution of triethanolamine $(0.38 \mathrm{~g}, 2.6 \mathrm{mmol})$ in dry THF $(10 \mathrm{~mL})$ under reflux was added dropwise a solution of prepolymer $14(5.00 \mathrm{~g}, 0.417 \mathrm{mmol})$ in dry THF (125 mL). After 1 $\mathrm{h}$ the reaction was cooled to room temperature and the product isolated by repeated precipitation from methanol at $-78{ }^{\circ} \mathrm{C}$ to furnish $\mathbf{1 7}$ as a clear colourless elastomer $(3.36$ g, $62 \%)$; IR $\left(\mathrm{CDCl}_{3}, \mathrm{KBr}\right) v_{\max } / \mathrm{cm}^{-1} 3436,3154,2961,2926,2854,1793,1729,1595$, 1522, 1463, 1413, 1380; ${ }^{1} \mathrm{H}$ NMR (400 MHz, $\left.\mathrm{CDCl}_{3}\right) \delta$ 0.80-0.85 (m), 1.07-1.26 (m), 1.60-1.70 (m), 2.71-2.75 (t, $J=5.0 \mathrm{~Hz}), 2.81-2.85(\mathrm{t}, J=5.5 \mathrm{~Hz}), 3.60-3.63(\mathrm{t}, J=5.0$ $\mathrm{Hz}), 3.88$ (s), 4.14-4.25 (m), 7.04-7.08 (m), 7.26-7.30 (m); ${ }^{13} \mathrm{C}$ NMR (100 MHz, $\mathrm{CDCl}_{3}$ ) $\delta 10.6-10.9,25.9-26.8,30.0-31.2,33.5-33.8,38.1-39.1,40.5,54.3,56.9,59.6,63.2,63.9$, 118.8, 129.4, 136.0, 136.2, 153.9; GPC (THF): $\mathrm{M}_{\mathrm{w}} 35,100, \mathrm{M}_{\mathrm{n}} 17000$.

\section{Results and discussion}

The initial focus of this investigation was the design of supramolecular urethane based polymers which feature end-groups that possess varying degrees of hydrogen bonding capability in order to realize 'tunable' materials. The end-groups were selected in line 
with our previous investigations ${ }^{17,18}$ in order to deliver materials that possessed a noncrystalline, yet interpenetrating, phase separated morphology. These design criteria are important as the introduction of physical, crystalline cross-links into non-covalently bonded polymeric materials has previously been shown to have a dramatic impact on the physical properties of the materials, over and above the hydrogen bonding interactions that we aimed to study. ${ }^{11,16}$ In addition, recent work by Sibjesma et al. has demonstrated ${ }^{19}$ that telechelic supramolecular polymers which assemble via end to end binding, but lack secondary lateral interactions, leads to one dimensional aggregation in the solid state and thus a lack of strength in the axis of the material perpendicular to the orientation of the hydrogen bonding system.

As part of this study, three relatively inexpensive residues based on a central aliphatic tertiary amine motif were selected as the polymer end-groups. The tertiary amine element acted as a hydrogen bonding acceptor whilst the non-planar geometry of this unit was predicted to hinder crystallization of the end-groups. Two of the substituents on the tertiary amine were either butyl groups (without hydrogen bonding capability), part of a cyclic ether (morpholine - which may be considered a hydrogen bonding acceptor), or two alcohol moieties (which can act as hydrogen bond acceptors and donors). Lastly, the end-group was introduced onto the isocyanate termini of the pre-polymer either via an alcohol (Figure 1, 1-3) or amine functionality (Figure 1, 4-6) to afford the corresponding urethane or urea moieties, respectively. We have shown previously that the addition of these end-groups (1-6) to methylene diphenyl diisocyanate (MDI) leads to polymeric-like materials. ${ }^{17}$ These materials possess an irregular hydrogen bonded array as a consequence of the conformational flexibility of the end-groups disfavoring supramolecular linear chain extension, delivering the three dimensional morphology that generates mechanical robust materials.
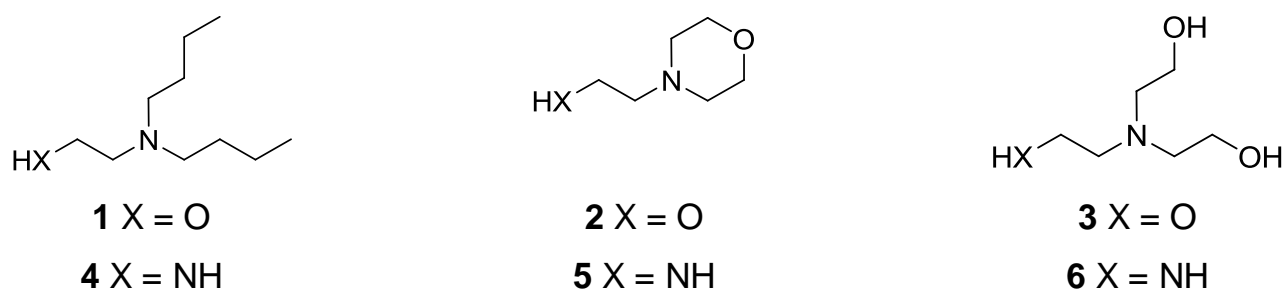

Figure 1 Structures of end-groups 1-6. 
Prior to the study of the self-assembling polymeric systems, model compounds featuring the hydrogen bonding end-groups (1-6) were synthesized ${ }^{17}$ to verify that their hydrogen bonding properties met the design criteria (7-12 in Table 1). Each model compound contained one of the end-groups in addition to an aliphatic group which was designed to replicate the polymer chain. ${ }^{20}$ In some cases it was necessary to use a branched aliphatic residue (2-ethyl hexanol) to aid the solubility of the final product. It was possible to ascertain the self-associative binding constants of these model compounds (7-12) in solution $\left(\mathrm{CDCl}_{3}, 25{ }^{\circ} \mathrm{C}\right)$. This was accomplished by measuring the change in position of the key NH proton resonances on the urethane (and/or the urea when present) with respect to concentration. ${ }^{17}$ The binding constants for the six model compounds are reported in Table 1 (see Supporting Information).

\begin{tabular}{|c|c|c|c|}
\hline \multirow[t]{2}{*}{ Compound } & \multicolumn{2}{|c|}{$K_{\mathrm{a}} / \mathrm{M}^{-1}$} & \multirow[t]{2}{*}{$\mathrm{R}_{1}$} \\
\hline & $X=O$ & $\mathrm{X}=\mathrm{NH}$ & \\
\hline & $\begin{array}{c}7 \\
1.4 \pm 0.4\end{array}$ & $\begin{array}{c}10 \\
6.9 \pm 1.7\end{array}$ & $\begin{array}{c}\mathbf{7}=\text { undecane } \\
\mathbf{1 0}=\text { 2-ethylhexane }\end{array}$ \\
\hline & $\begin{array}{c}\mathbf{8} \\
1.5 \pm 0.3\end{array}$ & $\begin{array}{c}11 \\
9.7 \pm 4.5\end{array}$ & $\begin{array}{c}\mathbf{8}=\text { undecane } \\
\mathbf{1 1}=\text { 2-ethylhexane }\end{array}$ \\
\hline & $\begin{array}{c}9 \\
15^{17}\end{array}$ & $\begin{array}{c}12 \\
45 \pm 11\end{array}$ & $\begin{array}{c}\mathbf{9}=\text { decane } \\
\mathbf{1 2}=2 \text {-ethylhexane }\end{array}$ \\
\hline
\end{tabular}

Table 1 Structures and binding constants $\left(\mathrm{CDCl}_{3}, 25^{\circ} \mathrm{C}\right)$ for the model compounds

\section{7-12}

As predicted, the binding constants for the model compounds correlated with increasing hydrogen bonding potential of the end-groups in the order dibutyl<morpholine<diol within the series of compounds that contained either two urethane moieties $(\mathbf{7}, \mathbf{8}$ and $\mathbf{9})$ or a combination of a urea and a urethane functionality $(\mathbf{1 0}, 11$ and 12). In each case, the binding constant for the model compound that contained both urea and urethane groups was higher than that for the analogous model compound that contained two urethane groups. In all cases, the binding constant was low (between 1 and $45 \mathrm{M}^{-1}$ ), far below that needed to produce an appreciable DP in dilute solution. ${ }^{8}$ 
With this data in hand, attention turned to the synthesis of the polymeric systems (15-20) which would be modified to contain the end-groups 1-6. The synthesis of these supramolecular polymers was achieved by the addition of two equivalents of the alcohol or amine functionalized end-groups (1-6) to a pre-polymer (14) synthesized by the addition of MDI to poly(ethylene-co-butylene) diol (13, [P(E-co-B)]) (NCO to $\mathrm{OH}$ ratio $2: 1$ ), according to our previously established methodology ${ }^{18}$ (Scheme 1) in order to deliver a prepolymer with a predicted molecular weight of $12 \mathrm{kDa}$ (see Supporting Information). We predicted that the non-polar nature of $\mathrm{P}(\mathrm{E}-\mathrm{co}-\mathrm{B})$ would induce phase separation from the polar, hydrogen bonding end-groups and aid the delivery of the desired supramolecular hydrogen bonded elastomers. 


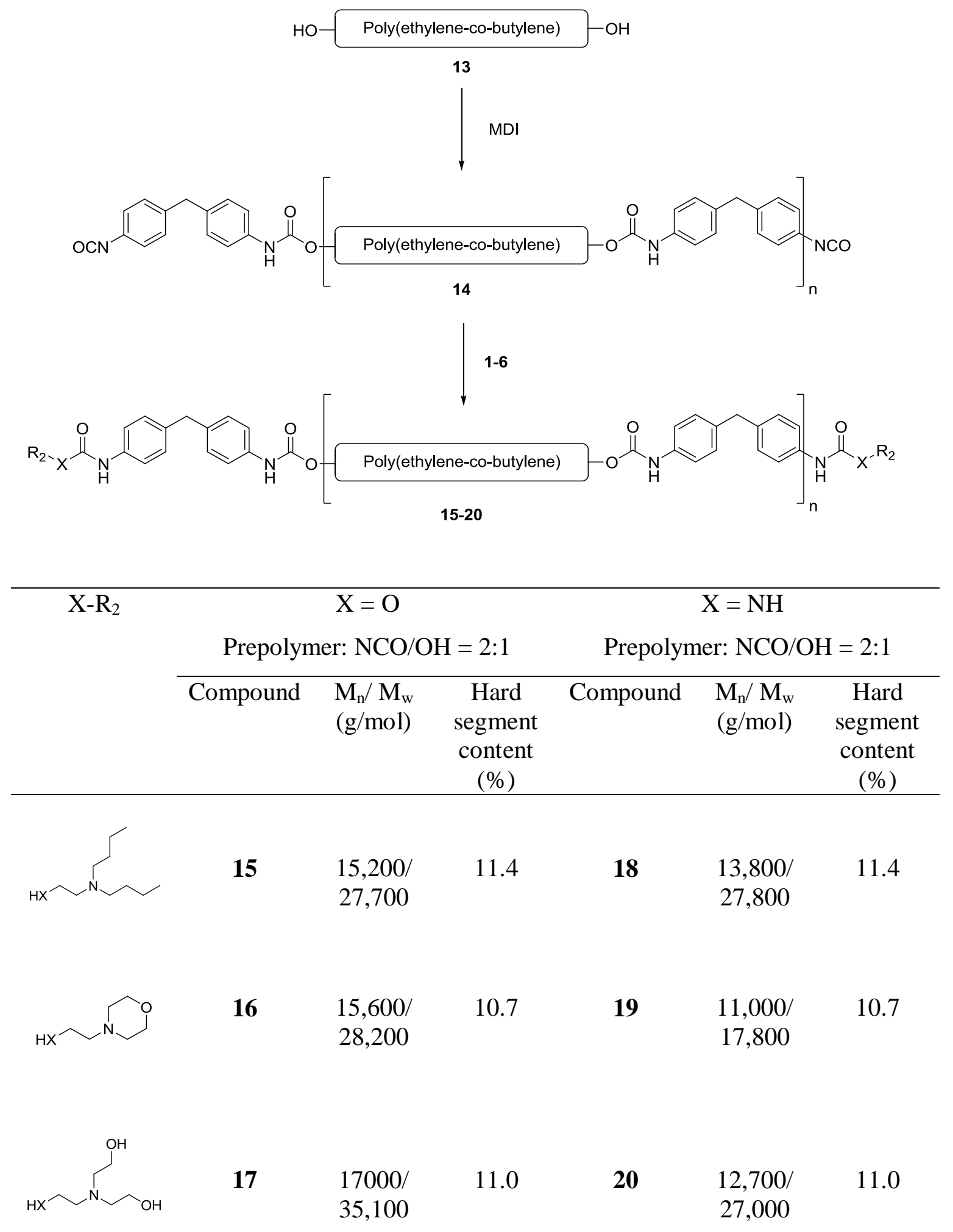

Scheme 1 Synthesis and structures of supramolecular self-assembling polymers 15-20. 
As a consequence of the high reactivity of the prepolymer isocyanate endgroups, the molecular weight of $\mathbf{1 4}$ could not be measured directly. However, the averaged $M_{n}$ value of the polymers $\mathbf{1 5 - 2 0}$ was $14 \mathrm{kDa}$ as determined by GPC analysis, which was comparable to the targeted molecular weight of $12 \mathrm{kDa}$.

Each of the supramolecular polymers $\mathbf{1 5}$ to $\mathbf{2 0}$ was isolated as a rubbery-like material which was soluble in organic solvents such as chloroform and THF. In contrast to the pre-polymer 14, a sticky viscous material at ambient temperature, the polymers (15 to 20 ) could be solution cast to form optically transparent, self-supporting elastomeric films, thus demonstrating the effect that the end-groups have on the physical properties of the $\mathrm{P}(\mathrm{E}-\mathrm{co}-\mathrm{B})$ prepolymer 14 . It should be noted that as a consequence of the closely related composition of the polymers (15-20), each contained essentially the same proportion of hard block segments $(11 \%+/-0.4 \%)$. Therefore, differences in the morphology and mechanical performance within this series of polymers must be related to the small structural changes within the end-group of each polymer.

To confirm that these polymers met the design criteria (vide supra) each of the samples was analysed by solid state FTIR and differential scanning calorimetry (DSC). The FTIR spectra for the polymers containing end-groups appended to the pre-polymer (14) via a urethane linkage (15-17) or urea linkages (18-20) are shown in Figures 2a and b, respectively. The FTIR spectra for urethane terminated polymers 15-17 all exhibited strong absorbances for both the free $\left(1730 \mathrm{~cm}^{-1}\right)$ and hydrogen bonded $\left(1710 \mathrm{~cm}^{-1}\right)$ urethane groups. ${ }^{21}$ This spectroscopic data suggests that a proportion of the urethane groups are distributed throughout the soft segment, rather than constrained within densely hydrogen bonded hard segments. ${ }^{16}$ In addition, IR spectroscopic analysis of polymers 1820 (which contain both urethane and urea moieties), revealed absorbance bands corresponding to both free and hydrogen bonded urethane groups $\left(1730 \mathrm{~cm}^{-1}\right.$ and 1710 $\mathrm{cm}^{-1}$, respectively) as well as intense bands indicative of disordered urea stacking (1660$\left.1680 \mathrm{~cm}^{-1}\right)$. Absorbances consistent with ordered urea domains $\left(\mathrm{ca} .1630 \mathrm{~cm}^{-1}\right)$ were, in contrast, relatively weak indicating that these materials did not feature significant crystalline domains, in line with our original design criteria. 


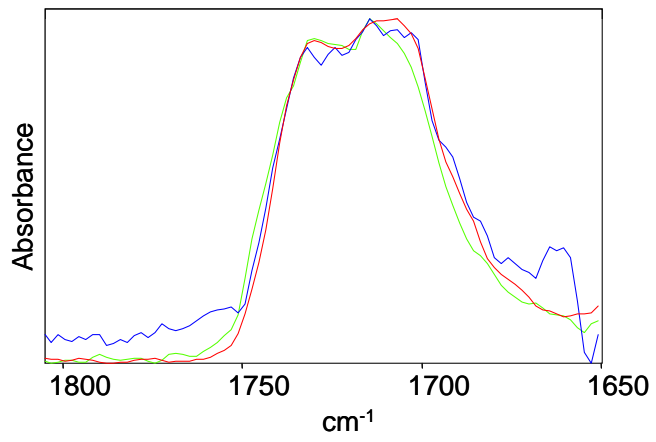

15
17

a

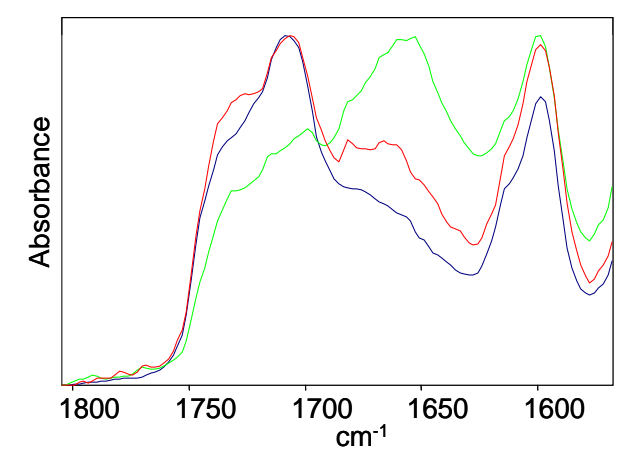

18

b

Figure 2 (a) Partial FTIR spectra for polymers 15-17 and (b) polymers 18-20.

Furthermore, the absence of crystallinity within all six polymers (15-20), was confirmed by DSC analysis (see Supporting Information). Melting exotherms were not observed during either the heating or cooling cycles thus demonstrating the desired amorphous morphology in all of these polymers. However, each thermogram featured a readily identifiable glass transition at $c a .-60{ }^{\circ} \mathrm{C}$, typical of that expected for the $\mathrm{P}(\mathrm{E}-\mathrm{co}-\mathrm{B})$ soft segment.

To obtain a deeper understanding of the morphology of these materials, polymers 15-20 were analysed by both wide angle X-ray scattering (WAXS) and small angle X-ray scattering (SAXS). Analysis of the WAXS scattering patterns confirmed the lack of crystallinity of the end-groups but revealed the local packing of the self-assembled polymer network through the planar hydrogen bonds between the urethane or urea groups. All of the WAXS scattering patterns featured an isotropic halo at $2 \theta$ which indicated a lattice spacing of $4.7 \AA$ for the stacking of the urethane/urea moieties. ${ }^{22}$ This lattice spacing was consistent regardless of the polymer end-group under analysis.

Each of the polymers (15-20) exhibited a single Bragg peak in the SAXS profiles, suggesting a microphase separated morphology on the 5.9-8.1 nm length scale (Figure 3). The phase separation is driven by the immiscibility of the hard, hydrogen bonding endgroups within the soft, non-polar central P(E-co-B) blocks. The intensity of the scattering 
signal increased with the type of end-group in the order dibutyl<morpholine $<$ diol. For each of these end-groups, the urethane/urea containing polymers (18-20) produced scattering signals with higher intensity when compared to the polymers (15-17) that possessed only urethane moieties. The relationship between the dilute solution binding constant for the end-groups and the bulk peak scattering intensity is illustrated in Figure 3.
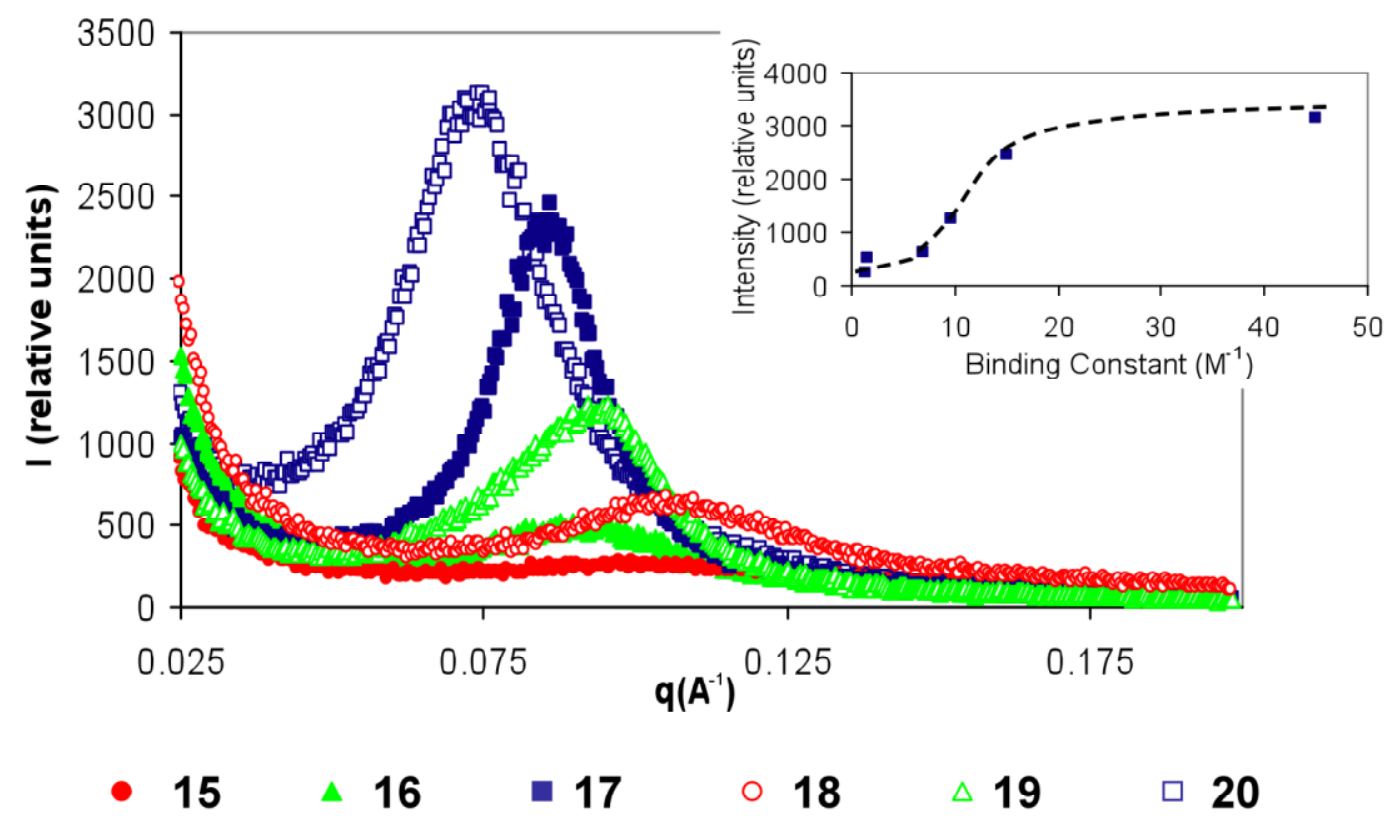

Figure 3 SAXS analysis of polymers $15-20$ at $25{ }^{\circ} \mathrm{C}$. (Insert) plot of peak scattering intensity versus binding constant.

The intensity of the scattering signal is related to the degree of phase separation, and therefore increasing the binding constant increases the phase separation between the soft and hard sections. It can be seen for polymers 15-17 which contain end-groups with very low binding constants ( $c a .1$ to $7 \mathrm{M}^{-1}$ ), there is little increase in the absolute scattering signal (250-600 units). In contrast, further increase in binding constant of the end group from $7-15 \mathrm{M}^{-1}(\mathbf{1 7 - 1 9})$ results in a dramatic increase in the scattering intensity from 500 to 2500 units. However, further tripling of the binding constant of the end group to 45 $\mathrm{M}^{-1}$ (20) had a much smaller effect on the degree of phase separation with the scattering intensity only increasing to $c a$. 3100 units. These data suggest that there is a minimum 
binding constant necessary to produce appreciable phase separation, but in addition there is a point at which maximum phase separation has been achieved and a further increase in binding constant only provides limited changes to the polymer morphology.

Rheological analysis of the supramolecular polymers (15-20) was carried out on a parallel plate rheometer operating at a constant frequency of $10 \mathrm{~Hz}$ with a temperature ramp of $3{ }^{\circ} \mathrm{C} / \mathrm{min}$. Storage moduli were measured as a function of temperature over the range $-75{ }^{\circ} \mathrm{C}$ to at least $100{ }^{\circ} \mathrm{C}$. All of the polymers appeared ${ }^{23}$ to exhibit a drop in storage modulus between $-35{ }^{\circ} \mathrm{C}$ and $-60{ }^{\circ} \mathrm{C}$ from $\mathrm{ca} .10^{7} \mathrm{~Pa}$ to $10^{6} \mathrm{~Pa}$, consistent with a phase transition occurring in the soft $\mathrm{P}(\mathrm{E}-\mathrm{co}-\mathrm{B})$ segments of the blend (Figure 4). The storage modulus for each polymer remained constant at this plateau $\left(\approx 10^{6} \mathrm{~Pa}\right)$ until beginning to reduce significantly as the temperature was increased. The end of the plateau region occurs at a temperature between $0{ }^{\circ} \mathrm{C}$ and $50{ }^{\circ} \mathrm{C}$, depending on the molecular structure of the material. This rheological profile is entirely consistent with a multiphase morphology and has been observed previously for a range of structurally diverse, segmented poly(urethanes) in the solid state..$^{24,25}$

The effect of structure on the rheological profile is further evident from the relationship between end-group binding constant in dilute solution and the temperature at which storage modulus for each polymer in bulk deviates from the plateau region (Figure 4, insert) (as defined by the temperature at which the storage modulus drops below $10^{5} \mathrm{~Pa}$ ). Thus, whilst the storage modulus of the polymers at low temperatures (i.e. below $0{ }^{\circ} \mathrm{C}$ ) is independent of the nature of the end-group, the temperature at which the storage modulus deviates from the plateau region is directly related to the binding constant. 


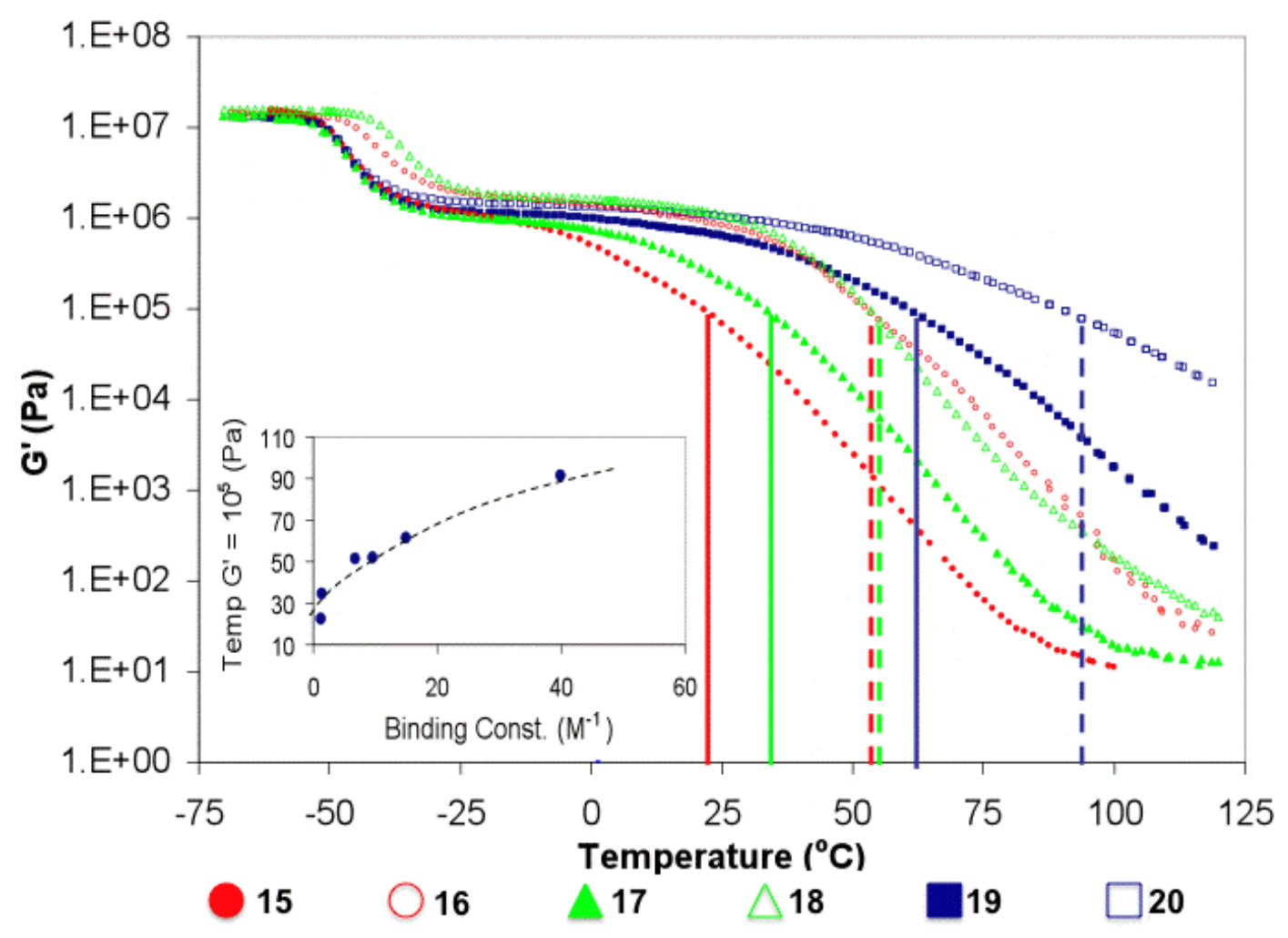

Figure 4 Variation of storage modulus with temperature for supramolecular polymers 1520. (Insert) Plot of end-group binding constant against the temperature at which the storage modulus for the respective polymers falls below $10^{5} \mathrm{~Pa}$.

The high thermal responsiveness of these polymers may be exemplified by studying the rheological response of the morpholine end-capped supramolecular polymer $19\left(\mathrm{M}_{\mathrm{n}}=\right.$ $11,000 \mathrm{~g} \mathrm{~mol}^{-1}$ ) which exhibits a reduction in storage modulus of 5 orders of magnitude from $10^{6} \mathrm{~Pa}$ between $50{ }^{\circ} \mathrm{C}$ and $100{ }^{\circ} \mathrm{C}$. The material is thus transformed from a tough rubber-like elastomer to a free flowing liquid. This is different to classic high molecular weight phase segmented poly(urethanes), which typically exhibit reductions in storage modulus of only three orders of magnitude to $10^{6} \mathrm{~Pa}$ at far higher temperatures (150-200 $\left.{ }^{\circ} \mathrm{C}\right) .{ }^{26}$

\section{Conclusions}

Through careful design we have synthesized six new thermoplastic elastomers which possess weakly hydrogen bonding end-groups. Our studies have shown that a variation of 
physical properties correlate systematically with the hydrogen bonding strength of the end-group. Binding constants in dilute solution, bulk SAXS peak scattering intensity and storage modulus above ambient temperature all increased when the end-group was changed from dibutyl<morpholine<diol and when the polymers contained urea groups. All of the polymers exhibited microphase separation in the bulk, and both the morphology and rheology correlated with the binding constant of the end-groups in dilute solution. These results signify an important design principle in the advance of supramolecular polymeric materials. We hope to develop further the observations made for this system to provide a general, predictive model for de novo design of supramolecular polymer materials.

\section{Acknowledgements}

The authors would like to thank Henkel UK Limited (post-graduate studentships for PW and DHM) and EPSRC (EP/D07434711, EP/G026203/1 - post-doctoral fellowships for BWG) and the University of Reading for financial support of this research.

\section{Supporting Information}

Full synthetic procedures, characterization and ${ }^{1} \mathrm{H}$ NMR binding studies for model compounds 7 and 8, 10-12. Calculation to estimate the molecular weight of prepolymer 14. Full synthetic procedures and characterization for polymers 16 and 18 to $20 .{ }^{1} \mathrm{H} \&{ }^{13} \mathrm{C}$ NMR spectra and DSC thermograms for polymers 15-20. This information is available free of charge via the Internet at http://pubs.acs.org/.

\section{References}

1 Brunsveld, L.; Folmer, B. J. B.; Meijer, E.W.; Sijbesma, R. P. Chem. Rev. 2001, 101, 4071-4097.

2 For recent reviews on the synthesis and properties of supramolecular polymers see:(a) Ciferri, A. Supramolecular Polymers; Marcel Dekker: New York, 2000. (b) Schmuck, C.; Wienand, W. Angew. Chem. Int. Ed. 2001, 40, 4363-4369. (c) Ciferri, A. Macromol. Rapid. Commun. 2002, 23, 511-529. (d) Sivakova, S.; Rowan, S. J. Chem. Soc. Rev. 2005, 34, 9-21. (e) South, C. R.; Burd, C.; Weck, M. Acc. Chem. Res. 2007, 40, 63-74. (f) Fox, J. D.; Rowan, S. J. Macromolecules 2009, 42, 68236835. 
3 Sijbesma, R. P.; Beijer, F. H.; Brunsveld, L.; Folmer, B. J. B.; Hirschberg, J. H. K. K.; Langer, R. F. M.; Lowe, J. K. L.; Meijer, E. W. Science 1997, 278, 1601-1604.

4 For reviews assessing recent developments in hydrogen bonded supramolecular polymers see: (a) ten Cate, A. T.; Sijbesma, R. P. Macromol. Rapid. Commun. 2002, 23, 1094-1112. (b) Shimizu, L. S. Polymer Int. 2007, 56, 444-452. (c) Wilson, A. J. Soft Matter 2007, 3, 409-425.

5 For examples of supramolecular polymer arrays formed via metal-ligand interactions see: (a) Michelson, U.; Hunter, C. A. Angew. Chem. Int. Ed. Engl. 2000, 39, 764-767. (b) Beck, J. B.; Rowan, S. J. J. Am. Chem. Soc. 2003, 125, 13922-13923. (c) Zhao, Y. Q.; Beck, J. B.; Rowan, S. J.; Jamieson, A. M. Macromolecules 2004, 37, 3529-3531. (d) Hofmeier, H.; Schubert, U.S. Chem. Soc. Rev. 2004, 33, 373-399.

6 (a) Ashton, P. R.; Claessens, C. G.; Hayes, W.; Menzer, S.; Stoddart, J. F.; White, A. J. P.; Williams, D. J. Angew. Chem. Int. Ed. Engl. 1995, 34, 1862-1865. (b) Asakawa, M.; Ashton, P. R.; Brown, G.R.; Hayes, W.; Menzer, S.; Stoddart, J. F.; White, A. J. P.; Williams, D. J. Adv. Mater. 1996, 8, 37-41. (c) Asakawa, M.; Ashton, P. R.; Brown, G. R.; Hayes, W.; Janssen, H. M.; Meijer, E. W.; Menzer, S.; Pasini, D.; Stoddart, J. F.; White, A. J. P.; Williams, D. J. J. Am. Chem. Soc. 1998, 120, 920-932. (d) Burattini, S.; Colquhoun, H. M.; Greenland B. W.; Hayes, W. Faraday Discuss. 2009, 143, 247-264; (e) Burattini, S.; Colquhoun, H. M.; Fox, J.; Friedmann, D.; Greenland, B. W.; Harris, P. J. F.; Hayes, W.; Mackay, M. E.; Rowan, S. J. Chem. Commun. 2009, $6717-6719$.

7 Cifferi A. Growth of Supramolecular Structures. 'Supramolecular Polymers' 2nd Ed., Taylor and Francis, 2005.

8 (a) Ky Hirschberg, J. H. K.; Beijer, F. H.; van Aert, H. A.; Magusin, P. C. M. M.; Sijbesma, R. P.; Meijer, E. W. Macromolecules 1999, 32, 2696-2705. (b) Folmer, B. J. B.; Sijbesma, R. P.; Kooijman, H.; Spek, A. L.; Meijer, E. W. J. Am. Chem. Soc. 1999, 121, 9001-9007. (c) Langer, R. F. M.; van Gurp, M.; Meijer, E. W. J. Polym. Sci. Part A: Polym. Chem. 1999, 37, 3657-3670. (d) Kautz, H.; van Beek, D. J. M.; Sijbesma, R. P.; Meijer, E. W. Macromolecules 2006, 39, 4265-4267.

9 (a) Park, T.; Zimmerman, S. C.; Nakashima, S. J. Am. Chem. Soc. 2005, 127, 65206521. (b) Park, T.; Todd, E. M.; Nakashima, S.; Zimmerman, S. C. J. Am. Chem. Soc. 2005, 127, 18133-18142. (c) Todd, E. M.; Quinn, J. R.; Zimmerman, S. C. Isr. J. Chem. 2005, 45, 381-389. (d) Park, T.; Mayer, M. F.; Nakashima, S.; Zimmerman, S. C. Synlett 2005, 1435-1436.

10 St. Pourcain, C. B.; Griffin, A. C. Macromolecules 1995, 28, 4116-4121.

11 Lillya, C. P.; Baker, R. J.; Hütte, S.; Winter, H. H.; Lin, Y.-G.; Shi, J.; Dickinson, L. C.; Chien, J. C. W. Macromolecules 1992, 25, 2076-2080.

12 Yilgor, I.; Yilgor, E. Polym. Rev. 2007, 47, 487-510.

13 Muller, M.; Dardin, A.; Seidel, U.; Balsamo, V.; Ivan, B.; Spiess, H. W.; Stadler, R. Macromolecules 1996, 29, 2577-2583.

14 Colombani, O.; Barioz, C.; Bouteiller, L.; Chaneac, C.; Fomperie, L.; Lortie, F.; Montes, H. Macromolecules 2005, 38, 1752-1759.

15 (a) Arun, A.; Gaymans, R. J. J. App. Polym. Sci. 2009, 122, 2663-2668. (b) Öjelund, K.; Loontjens, T.; Steeman, P.; Palmans, A.; Maurer, F. Macromol. Chem. Phys. 
2003, 204, 52-60. (c) Kuo, M. -C.; Jeng, R. -J.; Su, W.-C.; Dai, S. A. Macromolecules 2008, 41, 682-690.

16 Sivakova, S.; Bohnsack, D. A.; Mackay, M. E.; Suwanmala, P.; Rowan, S. J. J. Am. Chem. Soc. 2005, 127, 18202-18211.

17 (a) Woodward, P.; Clarke, A.; Greenland, B.W.; Hermida Merino, D.; Yates, L.; Slark, A. T.; Miravet, J. F.; Hayes, W. Soft Matter 2009, 10, 2000-2010. (b) Hayes, W.; Woodward, P. J.; Clarke, A.; Slark, A. T. EU Pat. EP792925, 2007.

18 Woodward, P.; Hermida Merino, D.; Hamley, I. W.; Slark, A. T.; Hayes, W. Aust. J. Chem. 2009, 62, 790-793.

19 Botterhuis, N. E.; van Beek, D. J.; van Gemert, G. M. L.; Bosman, A. W.; Sijbesma, R. P. J. Polym. Sci. A 2008, 46, 3877-3885.

20 Söntjens, S. H. M.; Sijbesma, R. P.; van Genderen, M. H. P.; Meijer, E. W. J. Am. Chem. Soc. 2000, 122, 7487-7493.

21 Ning, L.; De-Ning, W.; Sheng-Kang, Y.; Polymer 1996, 37, 3045-3047.

22 Kaushiva, B. D.; Wilkes, G. L. J. Appl. Polym. Sci. 2000, 77, 202-216.

23 It should be noted that the actual stiffness in the low temperature region (below -50 ${ }^{\circ} \mathrm{C}$ ) is likely to be higher than $10^{7} \mathrm{~Pa}$, because this is the upper limit of the modulus that can be measured using this instrument owing to the diameter of the plates used.

24 Sheth, J. P.; Klinedinst, D. B.; Wilkes, G. L.; Yilgor, I.; Yilgor, E.; Polymer 2005, 46, 7317-7322.

25 (a) Versteegen, R. M.; Kleppinger, R.; Sijbesma, R. P.; Meier, E. W. Macromolecules 2006, 39, 772-783. (b) O’Sickey, M. J.; Lawrey, B. D.; Wilkes, G. L. Polymer 2002, 43, 7399-7408. (c) O’Sickey, M. J.; Lawrey, B. D.; Wilkes, G. L. J. Appl. Polym. Sci. 2003, 89, 3520-3529.

26 Pukánszky Jr, B.; Bagdi, K.; Tóvölgyi, Z.; Varga, J.; Botz, L.; Hudak, S.; Dóczi, T.; Pukánszky, B. Eur. Polym. J. 2008, 44, 2431-2438. 


\section{For Table of Contents Use Only}

Hydrogen bonded supramolecular elastomers - Correlating hydrogen bonding strength with morphology and rheology

Philip J. Woodward, Daniel Hermida-Merino, Barnaby W. Greenland, Ian W. Hamley, Zoe Light, Andrew T. Slark and Wayne Hayes

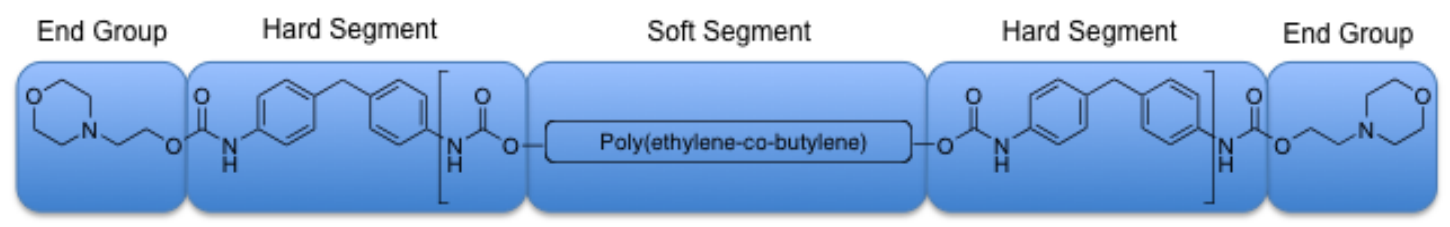

